\title{
Forms of address as Cross-Cultural Code-Switching: The case of German and Danish in Higher Education*
}

\author{
Bjarne Ørsnes (Kopenhagen)
}

\begin{abstract}
Both German and Danish have distinct pronouns for addressing communication partners formally and informally (referred to as $\mathrm{V}$ for Sie/De and $\mathrm{T}$ for $\mathrm{du} / \mathrm{du}$ ). However, their use differs considerably in Germany and Denmark, e. g. in higher education. In Germany, the lecturer and the students use V, in Denmark they use T. Based on the observation that Danish students are very reluctant (and sometimes even opposed) to use $\mathrm{V}$ in the classroom in Denmark, this article proposes to consider the use of $\mathrm{V}$ and $\mathrm{T}$ as a case of Cross-Cultural Code-Switching. It is hypothesized that $\mathrm{V}$ causes Cultural Cognitive Dissonance for (young) Danes since V is interpreted as an overt manifestation of power distance in a society which considers itself as egalitarian. Ways to cope with such cognitive dissonance in foreign language teaching are discussed. Furthermore, the article addresses the broader question of when cultural behaviours are supposed to apply and - in particular - what conventions are appropriate in higher education in Denmark when German is the language of instruction: should we use V as in Germany or T as in Denmark? Arguments for both choices are presented and discussed.
\end{abstract}

\section{Introduction}

As is well known, German belongs to the languages that (still) employ different pronouns to address communication partners, namely Sie and $d u / I h r$. The former is grammatically a third person plural pronoun, but can be used to address a single or more communication partners. This pronoun will be referred to as $\mathrm{V}$ for Latin vos. The latter pronouns are grammatically the second person singular and plural respectively and are used to address a single $(d u)$ or several communication partners $(I h r)$. These pronouns will be referred to as T for Latin $t u$. The use of these pronouns is complex and depends on a range of variables involving the formality of the situation, the relationship between speaker and hearer as well as inherent properties of the communication partners such as age and social position (for a comprehensive discussion, cf. Besch 1998). At the same time the use of the pronouns is subject to constant change.

\footnotetext{
* I wish to thank an anonymous reviewer, the audience at the SMIK-conference in Odense 25.2-27.2 2015, my colleagues in the research group Languages, ideologies and identities, and especially Maribel Blasco and Inger Mees for numerous discussions, comments and corrections. All remaining errors and shortcomings are my sole responsibility.
}

Linguistik online 79, 5/2016 - http://dx.doi.org/10.13092/lo.79.3342

CC by 3.0 
It is important for foreign learners of German to be aware of how to use these pronouns. Forms of address vary between cultures, and for learners of a foreign language forms of address are part of intercultural communicative competence as distinct from linguistic competence, which pertains only to a mastery of the linguistic code. ${ }^{1}$ A deviant use of forms of address may lead to disturbance in the communication, so interlocutors from different cultures should at least be aware of possible differences in the ways communication partners can be addressed.

There is a rich literature on the factors influencing the choice between $\mathrm{V}$ and $\mathrm{T}$ in German and in Danish and on the acquisition of these forms by foreign language learners. There are far fewer discussions as to why it may be difficult for (young) Danes to use V in German, and there are hardly any considerations of the issue which factors influence the choice between either the German or the Danish conventions of address. German conventions are expected to apply if one communicates with a German in Germany. ${ }^{2}$ But what if one communicates with a German in Denmark? Or if (for some reason) one wishes to speak German to a Dane in Denmark? Do the German or Danish conventions apply in these cases? This question becomes immediate relevant when we teach a foreign language in our home country. We have to decide whether to observe the conventions of the country where the language is spoken (or one of them if there are more) or the conventions of the country where the language is taught.

The following discussion is based on my own experiences as a native Dane following the German conventions, i. e. using V, when teaching in German in Denmark. This approach has not been well-received by my students, who hardly ever use V in German (neither in the classroom nor in written assignments targeting a German audience) and some students are even strongly opposed to using $\mathrm{V}$ in the classroom. Anonymous evaluations state that $\mathrm{V}$ is found to be detrimental to the learning environment and that $\mathrm{V}$ is in no way an appropriate form of address at a university in Denmark. Not only do these evaluations force us to reconsider the choice of address conventions in courses taught in German, they also force us to consider why (young) Danes find it such an effort to use V. An answer to this question will be suggested on the basis of an analysis of the use of $\mathrm{V}$ as Cross-cultural Code-Switching (cf. Molinsky 2007) where the speaker engages in a cultural behaviour, which may violate ingrained (culturally-based) values and attitudes. This violation in turn may result in Cultural Cognitive Dissonance (CCD) (cf. Maertz Jr. et al. 2009). It will be shown that there is reason to believe that the use of V triggers CCD for (young) Danes. However, it is worth pointing out that this CCD appears to stem from a classical interference error in this case: Danish and German V are interpreted differently and in this case students transfer their Danish interpretation to a German environment. If this hypothesis is correct, the problem must be dealt with in language teaching and below some suggestions are made as to how to do so.

\footnotetext{
${ }^{1}$ For ease of exposition I shall concentrate only on the pronouns used for address. Other linguistic means used for address will not be discussed, e. g. the use of first and last names and titles. These are also relevant in a German-Danish context of course but are beyond the scope of this article.

2 The present discussion focuses on the conventions in Germany, disregarding other German speaking countries such as Austria, (German-speaking) Switzerland or Liechtenstein. The article draws on experiences from teaching German at the Copenhagen Business School where the focus is on Germany as Denmark's principal trading partner. Possible differences in the use of $\mathrm{V}$ and $\mathrm{T}$ in different German speaking countries are not important for the points I wish to make, namely that forms of address can be seen as Cross-Cultural Code-Switching and that the factors determining the choice of cultural behaviours deserve more attention in the literature.
} 
In this specific case, the problem of choosing between $\mathrm{V}$ and $\mathrm{T}$ crops up because German and Danish higher education differ in their forms of address. In German higher education (in universities for example), the lecturer and students address each other symmetrically using $\mathrm{V}$ (while students use $\mathrm{T}$ among themselves). In Danish higher education, the lecturer and students symmetrically use $\mathrm{T}$ (as is the case almost everywhere else in the Danish society ${ }^{3}$ ). Of course it is possible to circumvent the problem by using $\mathrm{T}$ as in Denmark (thus violating the conventions of Germany). But is it correct to do so? Why not follow the conventions in Germany (if this is the country chosen as a point of reference)?

The question is complicated if German is used in a semi-authentic way as is the case in the German courses at the Copenhagen Business School. The courses show a close affiliation to the so-called CLIL-approaches (Content and Language Integrated Learning) where also nonlinguistic topics are taught in a foreign language for educational purposes. German is used as the language of instruction in order for the students (and maybe also the lecturer) to improve their language skills and German is employed to discuss topics like contemporary German society or business related issues. We are not dealing with language courses in the narrow sense and German is only to a limited extent the object of investigation. We are not recreating situations from German daily life for instructional purposes. It is a university class like other university classes, but it happens to be in German. Note, however, that German is not used as a lingua franca: The lecturer and students share another language, namely Danish. They are no native speakers of German, but still the interaction in class (and consequently the way of addressing each other) is spontaneous and not intended as an exercise to rehearse German ways of addressing communication partners.

The question of which conventions of address to choose is an important question for pedagogical reasons. It forces us to consider what kind of learning space we want to create as language teachers. Do we want the classroom to be a 'little Germany' or do we want it to be a 'Denmark in German'? Or do we want the classroom to be something in between, a "Third Place" (Kramsch 1993) - and if so, what should this Third Place look like? In addition, the issue is interesting for theoretical reasons since it forces us to consider what determines the applicability of cultural behaviours. When do we choose one convention over another?

This study is explorative in nature. The discussion below is based primarily on observations, and to some extent on answers from colleagues to specific questions. It has been important for me to observe what people do rather than to make people think about their practise and tell me about it. As a consequence, the discussion rests on a rather limited empirical basis and all conclusions, e. g. on the interpretation of the Danish V-form, should be understood as hypotheses. Furthermore, a comprehensive investigation of the attitudes of Danish learners of German to German culturally-based behaviours should include other means of interactional behaviour such as the use of first and last names as well as ways of greeting, thanking and interrupting in interactional discourse. ${ }^{4}$ The present study, however, restricts itself to presenting

\footnotetext{
${ }^{3}$ As a reviewer correctly points out, a tendency to use $\mathrm{V}$ in fashionable shops and hotels in Denmark can be observed. This use of $\mathrm{V}$ serves to convey an exclusive image and it works only because it stands out from the unmarked use of $\mathrm{T}$. In this sense, this use of $\mathrm{V}$ does not constitute a counter-example to $\mathrm{T}$ being the default form of address in Denmark. On the contrary, it is only possible because $\mathrm{T}$ is the default.

${ }^{4} \mathrm{I}$ am grateful to an anonymous reviewer for making this point.
} 
some specific hypotheses and to providing a framework for future investigations of these issues. At the same time it raises the fundamental question: "How do we go about teaching culturally-based behaviours at home"?

The paper is structured as follows. In section 2, the address conventions in German and Danish higher education are discussed. In sections 3 and 4, forms of address are analysed as Cross-Cultural Code-Switching, and strategies for coping with this phenomenon are presented. In section 5, some examples are given of how other people go about choosing between different sets of address conventions. These examples have partly been derived from the literature, partly based on personal observations. In section 6, I present some arguments in favour and against the use of $\mathrm{V}$ in Danish higher education when German is the language of instruction. Finally a conclusion is drawn providing some recommendations for the choice between $\mathrm{V}$ and $\mathrm{T}$ in higher education.

\section{Forms of address in higher education in Germany and Denmark}

As mentioned in the introduction, the use of $\mathrm{V}$ and $\mathrm{T}$ in Germany (and presumably almost all other countries with this distinction) is highly complex. In this brief discussion the focus will be on V/T in higher education. Bayer (1979) and Besch (1998) observe that that two different systems are in use in German universities. ${ }^{5}$ The two systems are shown below in a slightly simplified form and with my translations.

\begin{tabular}{|l|l|l|l|c|}
\hline \multicolumn{2}{|l|}{ System 1: } & $\begin{array}{l}\text { All communication partners ex- } \\
\text { (ept for intimate friends }\end{array}$ & $\begin{array}{l}\text { Recognition as a re- } \\
\text { sponsible fellow citi- } \\
\text { zen }\end{array}$ & Formal \\
\hline Marked & $D U^{l}$ & $\begin{array}{l}\text { Intimate acquaintances and } \\
\text { friends }\end{array}$ & $\begin{array}{l}\text { Intimacy developed } \\
\text { during the interaction }\end{array}$ & $\downarrow$ \\
Informal \\
\hline
\end{tabular}

Table 1: The use of German Sie and $d u$ in System 1 (sligtly modified from Bayer 1979)

\begin{tabular}{|c|c|c|c|c|}
\hline \multicolumn{5}{|l|}{ System 2: } \\
\hline $\begin{array}{l}\text { Unmarked } \\
\text { (Default) }\end{array}$ & $D U^{2}$ & $\begin{array}{l}\text { All communication partners in a } \\
\text { group where solidarity exists or } \\
\text { where solidarity is required }\end{array}$ & $\begin{array}{l}\text { Solidarity, } \\
\text { common interests, } \\
\text { in-group }\end{array}$ & Solidarity \\
\hline Marked & $S I E^{2}$ & $\begin{array}{l}\text { Partners with higher social posi- } \\
\text { tion or belonging to a group with } \\
\text { other interests }\end{array}$ & $\begin{array}{l}\text { Distance, conflict with } \\
\text { socially established } \\
\text { role structure, } \\
\text { out-group }\end{array}$ & Social distance \\
\hline
\end{tabular}

Table 2: The use of German Sie and $d u$ in System 2 (sligtly modified from Bayer 1979)

\footnotetext{
5 Bayer (1979) presents these systems in the context of higher education, but Vismans (2009) cites Durrell (2007) as claiming that the two systems are not restricted to higher education. Also, certain discussions in Bayer about e. g. modes of address in the army and among colleagues in the work place seem to indicate that the two systems are not necessarily restricted to higher education (cf. Bayer 1979: 214).
} 
In system 1 the basic opposition is that of formal vs. informal/intimate. The unmarked (default) mode of address is $\mathrm{V}$, which is used for all communication partners except for intimate friends. According to Bayer (1979), V expresses recognition as a responsible fellow citizen 6 and $\mathrm{T}$ is the marked mode of address expressing intimacy developed in the course of the interaction. A transition from $\mathrm{V}$ to $\mathrm{T}$ is based on mutual agreement.

In system 2, the basic opposition is solidarity vs. social distance among the interlocutors. $\mathrm{T}$ is the unmarked (default) mode, being used in groups where solidarity is assumed to exist or where solidarity is required. $\mathrm{V}$ in turn is used when the interlocutor has a higher social position or when (s)he belongs to a group with other interests or beliefs. According to Bayer (1979), system 2 was an offshoot from the student revolution in the 1960s, with the students using $\mathrm{T}$ among each other, and $\mathrm{V}$ when addressing lecturers. The lecturers remained within system 1 using V. So both lecturers and students used V to address each other, though with different interpretations in accordance with the two systems 1 and 2 (formal/recognition as a responsible citizen vs. social distance/out-group). What appears to be a uniform mode of address is in fact the result of one linguistic form having different interpretations. Bayer does not comment on the frequency of use of the two systems. Besch (1998) notes that the T mode has become established as the mode of address among students, but he does not comment on the mode of address between lecturers and students. Kretzenbacher (2010) and Cook (2014) hold that system 1 is dominant in contemporary Germany, interpreting $\mathrm{V}$ as an expression of neutral social and power distance. Whatever the exact interpretation of $\mathrm{V}$, it is undoubtedly the default form of address between lecturers and students in Germany as also indicated in Bayer (1979). Note further, that the basic opposition between $\mathrm{V}$ and $\mathrm{T}$ is not primarily one of power distance, neither in system 1 nor in system 2 .

A contextual factor favouring the use of $\mathrm{V}$ in higher education in Germany is the formality of the situation and the fact that teaching is a professional (semi-)public situation. $\mathrm{V}$ indexes the immediate context and defines it as a professional situation, where the communication partners are assigned specific roles (cf. Morford 1997: 16, for French). The importance of the formality of the situation for the choice between $\mathrm{V}$ and $\mathrm{T}$ can be illustrated with an occurrence I witnessed in another professional environment with pre-defined roles, namely an interview on public television. In August 2014, the foreign correspondent in Israel for the German public channel ARD conducted an interview in German with an Israeli woman of Austrian ancestry. After addressing her using $\mathrm{T}$ (and first name), he turned to the camera and explained that he was not going to pretend not to know her well by using $\mathrm{V}$. The journalist conformed to the rule of using $\mathrm{T}$ among friends, but at the same time he violated the rule of using $\mathrm{V}$ in a formal situation. Since the two rules were in conflict, he felt obliged to explain to the audience why he was using $\mathrm{T}$ in a formal situation. The fact that the use of $\mathrm{T}$ calls for an explanation, testifies to $\mathrm{V}$ being the unmarked form of address in a professional, (semi-)public situation and higher education counts as such a professional situation.

\footnotetext{
${ }^{6}$ It is a matter of debate whether pronouns of address have intrinsic values at all. Heringer (2009) suggests that pronouns of address acquire their interpretation during the actual interaction. This is why the canonically polite form Sie can also become very impolite, if used in a situation where $d u$ is expected (cf. also Morford 1997: 22). I follow Heringer and avoid assigning the pronouns of address intrinsic values such as "polite" or "formal".
} 
Denmark appears to have only one system for higher education (and elsewhere), with $\mathrm{T}$ as the unmarked form and $\mathrm{V}$ as a very marked form. ${ }^{7} \mathrm{~T}$ is almost a neutral form of address in Denmark, but crucially Danish (contrary to English with only one neutral form, cf. Cook 2014) does have a distinct $\mathrm{V}$ and therefore it is legitimate to speak of a marked and an unmarked form of address. As far as $\mathrm{V}$ is concerned, two different uses can be distinguished: unindividuated and individuated address. Un-individuated address is used to address an anonymous communication partner as found in public announcements and on signposts. Here $\mathrm{V}$ is occasionally found, e. g. on the websites of certain Danish newspapers or at Copenhagen airport:

- “Vi ønsker Dem en god rejse” ['we wish you.V a pleasant journey']

Individuated address refers to address of a known communication partner and here the use of $\mathrm{V}$ is extremely marked, especially in face-to-face communication.

The question is what interpretation is associated with individuated $\mathrm{V}$ in contemporary Denmark. A hint can be found by looking at discourse where the distinction between $\mathrm{V}$ and $\mathrm{T}$ is explicitly discussed. In 2011, the Danish journalist and musician Torben Steno published a book on the lack of politeness in contemporary Denmark. He even recommended a revival of $\mathrm{V}$ in everyday interaction in Denmark. In a subsequent interview in the Danish newspaper Politiken, the interviewer first associates V with "a stiff collar":

- Så du vil tilbage til stiv flip og krave og veere des"? [,So you want to return to a stiff collar and the use of the polite form?'] $]^{8}$

In the subsequent question the interviewer asks Torben Steno if he also wants to re-introduce hierarchies between people:

- "Vil du også have hierarkierne mellem mennesker tilbage?" ['Do you also want to re-introduce hierarchies between people?’].

Interestingly, the interviewer automatically associates $\mathrm{V}$ with hierarchies, i. e. with power distance - and even with physical discomfort (stiff collar). This same association is found in other discussions of the book, e. g. in internet fora:

- "Man kan sagtens vare høflig uden at have specifikke tiltaleformer hvor underdanighed er implicit" ['You can easily be polite without using forms of address that implicitly signal subservience']. ${ }^{9}$

Again, $\mathrm{V}$ is clearly associated with power distance and this may also explain why $\mathrm{V}$ is more often than not considered to be impolite (cf. Bryld 2011). The speaker signals reluctance to engage in any kind of relationship with the hearer by implying that speaker and hearer are not on the same level, that they are not equal. Absence of equality means exclusion of the addressee on the grounds of not belonging to the community where solidarity is supposed to exist. Thus there are clear indications that $\mathrm{V}$ is measured along a scale of power distance (cf. Brown/Gilman 1960) in Danish.

\footnotetext{
${ }^{7}$ This system was established in the 1960s - especially as an offshoot of the student revolution.

${ }^{8}$ The interview can be found at http://politiken.dk/debat/ECE1475229/68erne-har-skabt-engraenseoverskridende-uhoeflighed/ [29.01.2016].

${ }^{9}$ See e. g. https://da-dk.facebook.com/politiken/posts/104929006292032 [29.01.2016].
} 
The previous discussion suggests that the opposition between $\mathrm{T}$ and $\mathrm{V}$ in Danish is one of equality vs. non-equality as depicted in the table below:

\begin{tabular}{|c|c|c|c|c|}
\hline $\begin{array}{l}\text { Unmarked } \\
\text { Default }\end{array}$ & $d u$ & All communication partners & "We are all equal" & $\begin{array}{c}\text { Equal } \\
\uparrow\end{array}$ \\
\hline $\begin{array}{l}\text { Very } \\
\text { marked }\end{array}$ & $D e$ & Exclusion (disrespect) & $\begin{array}{l}\text { Distance } \\
\text { Distancing one-self } \\
\text { from others }\end{array}$ & $\begin{array}{c}\downarrow \\
\text { Non-equal }\end{array}$ \\
\hline
\end{tabular}

Table 3: The use of Danish $D e(\mathrm{~V})$ and $d u(\mathrm{~T})$

Using the two scales of power distance and social distance from Brown/Gilman (1960) and Leech (1983: 126) we can sum up the discussion so far and provide a clear picture of the differences between V in German and Danish. German V is measured along the scale of social distance: $\mathrm{V}$ means socially distant. Danish $\mathrm{V}$, in turn, is measured along the scale of power distance: $\mathrm{V}$ means hierarchically distant. Furthermore, $\mathrm{V}$ is the unmarked form of address in German (cf. also Weinrich 2003: 104; Kretzenbacher 2010: 16; Cook 2014: 18), while $\mathrm{T}$ is the unmarked form in Danish (a point also made by Rasmussen 1998). Given these considerable differences we now have parts of the answer as to why young Danes have difficulties using V.

\section{German V as Cross-cultural code-switching}

The use of V in German can be analysed as a case of Cross-Cultural Code Switching (CCS) for Danish learners. Molinsky (2007) defines CCS as the act of purposefully modifying one's behaviour in a foreign setting in order to accommodate different cultural norms for appropriate behaviour (cf. Molinsky 2007: 624). According to this definition, the use of $\mathrm{V}$ is indeed a case of CCS for Danes since they have to modify their behaviour in order to be able to address German communication partners appropriately. Molinsky illustrates CCS with nonverbal behaviours, but the use of $\mathrm{V}$ is actually a very good illustration of CCS. Codeswitching as known from sociolinguistics refers to a verbal act where bilingual speakers switch between languages when speaking to other bilinguals and the use of $\mathrm{V}$ is a verbal cultural behaviour. Still, the definition as it stands highlights a crucial problem already alluded to in the preceding discussion: it is not clear to what extent the instructional setting referred to counts as "a foreign setting". Put differently, is the actual use of a foreign language sufficient to count as a foreign setting? As we will see later, the students appear not to consider this a foreign setting, even though the lecturer tries to make them do so.

According to Molinsky, CCS involves two psychological challenges: 1) task performance: the ability to execute a novel set of behaviours and 2) an identity dimension: the ability to come to terms with the personal implications of the foreign behaviour. Foreign language instruction canonically pays much attention to task performance. Students learn to distinguish between V and $\mathrm{T}$ and they learn the appropriate conditions for the use of $\mathrm{V}$ and $\mathrm{T}$ in the foreign culture. The identity dimension is usually neglected even though the new behaviour may cause a psychological resistance for personal reasons. In Molinsky's terms, CCS can be associated with a 'psychological toll', and Molinsky discusses several variables that may have an impact on this 
psychological toll. One of these is the degree of discrepancy between the norms in the foreign culture and in the native culture. This variable is relevant for the use of $\mathrm{V}$ in Germany and Denmark since $\mathrm{V}$ is the unmarked form of address in Germany, and $\mathrm{T}$ is the unmarked form of address in Denmark. If the new behaviour conflicts with already established values and beliefs, such a discrepancy may result in Cultural Cognitive Dissonance (CCD), i.e. any threat to the self-concept from some perceived inconsistency with either normative standards or uniquely personal standards of competence and morality (cf. Maertz Jr. et al. 2008: 68). The question is to what extent $\mathrm{V}$ can be expected to cause Cultural Cognitive Dissonance for young Danes.

\section{Cultural Cognitive Dissonance}

The following quote from an anonymous student evaluation from a course taught in German at the Copenhagen Business School strongly suggests that V causes CCD:

One last thing that does not contribute to a good learning environment in class: We are in Denmark therefore it seems very awkward to have to say "De" (the Danish V-form, BØ) to NN, when other teachers do not require it either. As already mentioned: We are in Denmark at a Danish university.

(Anonymous student evaluation, June 2013, my translation)

This student considers the use of V to be detrimental to the teaching environment. (S)he does not develop this point, but the student's following remark gives a hint: The student understands $\mathrm{V}$ to be a form used asymmetrically by the students to address the teacher, in fact it is even a requirement from the teacher. This is a very telling re-interpretation of the facts in the mind of the student. In Germany, $\mathrm{V}$ is used symmetrically in higher education and the students are told so in the beginning of the course. ${ }^{10}$ However, the student understands $\mathrm{V}$ in the Danish context and interprets $\mathrm{V}$ along the asymmetric scale of power distance (see section 2): the students have to employ $\mathrm{V}$ when speaking to the lecturer because he ranks higher in the hierarchy of power. This interpretation is superimposed on the learning situation as a whole. Since learning is expected to take place in a supportive and collaborative atmosphere, $\mathrm{V}-$ interpreted as an expression of power distance and even subservience on the part of the speaker - is felt to be detrimental to the learning environment. In fact, this understanding of $\mathrm{V}$ is felt to be a violation of a fundamental value in Danish society, namely that everyone is equal and that the teacher is a mentor rather than an instructor.

Numerous anthropological analyses of contemporary Danish society emphasize the importance of egalitarianism as a fundamental value of this society. Danish society conceives of itself as egalitarian and is opposed to overt manifestations of hierarchical distance. This should not necessarily be taken to mean that hierarchies do not exist in Danish society, but they are not supposed to be manifest. Jenkins (2011) provides various examples of evidence to support this view and even explains the lack of an equivalent for the English politeness phrase please in Danish with reference to the idea that everyone is considered to be equal. Please is used to initiate an interaction (much as $\mathrm{V}$ and $\mathrm{T}$ ), but equals do not need to establish

\footnotetext{
${ }^{10}$ However, in this particular course the use of $\mathrm{V}$ was involuntarily asymmetric, inasmuch as the students addressed the teacher using $\mathrm{T}$, while the teacher addressed the students using $\mathrm{V}$.
} 
common ground prior to the conversation. Instead, equals tend to thank the communication partner for any favour exchanged in the interaction to restore the equilibrium between the interlocutors (cf. Leech 1983: 125). Jenkins (2011) points to the abundance of phrases of thanking in everyday conversations in Denmark. He even traces the historical roots of the idea of egalitarianism (cf. Jenkins 2011: 45) to the Danish nation building process which emphasized the cultural, social and economic homogeneity of a small country: we are all the same. Knudsen (1996) arrives at a similar conclusion. She observes that discussions in Denmark usually take place sitting at a round table to avoid having someone sitting at the end of the table (and at the same time sitting alleviates height differences). Fink (2012: 66) attributes Denmark's low score on the scale of power distance in Hofstede (1991: 36) to the importance of equality in Danish society and to the fact that equality is deeply ingrained in the Danes. Nørmark (2011: 76-79, 86-90), too, describes Denmark as an egalitarian society, and Fredsted (2004: 159) observes that overt manifestations of superiority or hierarchies are not considered good form in Denmark. Møller (2008: 27), finally, arrives at a similar conclusion, noting that the German workplace is more hierarchical than the Danish (at least at a superficial level) and that these hierarchical differences are reflected in the different uses of $\mathrm{V}$ and $\mathrm{T}$.

On the basis of these analyses of Danish culture we have reason to believe that the use of $\mathrm{V}$ triggers CCD among (young) Danes. If $\mathrm{V}$ is indeed understood as expressing power distance (as hypothesized in section 2), $\mathrm{V}$ is felt to be a threat to the self-concept, i.e. to the image Danes have of themselves as being egalitarian. It is conceived of as an overt manifestation of inequality, thus violating deeply ingrained values and beliefs of equality. Moreover, CCD is exacerbated by the fact that the lecturer is Danish himself. There is no external motivation for executing a set of foreign behaviours, the lecturer being a member of the same culture.

Two further aspects possibly contributing to CCD deserve to be mentioned. The first one concerns the very fact that the students adopt a behaviour from a foreign culture by using V. As we have seen, Jenkins (2011) (among many others) points out that Denmark strives to be a very homogeneous society. It is not considered acceptable to stand out from the group. By adopting a foreign behaviour, one distances oneself from one's peers. This was already the topic of the play Jean de France (1722) by the national poet Ludvig Holberg. Jean de France was the son of a Danish farmer who returned from a trip to Paris with French manners much to the dismay of his old friends and family.

The second point concerns the impact of a foreign language on the learning environment. In a study on the interaction between teachers and students in CLIL-courses in Finland, Nikula (2010) observes that there is more turn-taking between students and teacher in courses taught in English, than in courses taught in their mother tongue, Finnish. She speculates that English as a common foreign language puts the lecturer and the students on a more equal footing. Students and lecturer are equally restricted in their ability to express themselves. Using his/her mother tongue, however, the lecturer is able to establish himself/herself as an authoritative teacher (cf. also Preisler 2014). The same phenomenon with a different outcome can be observed in the instructional context under discussion here: the lecturer starts from a position of authority by being more proficient in the foreign language than the students. The students in turn are more likely to feel linguistically inferior and are not able to express themselves and 
to interact in the way they are used to in their mother tongue (see also the discussion in Harder 1980). The use of $\mathrm{V}$ makes an already perceived inequality explicit.

\subsection{Coping with Cultural Cognitive Dissonance}

If the use of $\mathrm{V}$ causes $\mathrm{CCD}$, language instruction should find ways to help the students cope with it. Maertz Jr. et al. (2009) discuss several strategies to reduce cultural cognitive dissonance:

1. VABN (Values, Attitudes, Beliefs and Norms) modification: the individual VABNs are changed according to the foreign culture. In the case at hand, one comes to value the distinction between $\mathrm{V}$ and $\mathrm{T}$, also in one's native culture.

2. Perceptual modification: the perception of the VABN underlying the foreign behaviour is changed. This means that $\mathrm{V}$ is understood in a German setting: $\mathrm{V}$ is not associated with a power distance, but rather with non-intimacy or a professional context.

3. Self-affirmation: one copes with the discomfort of the foreign behaviour by highlighting other positive values of oneself. Thus one could reassure oneself that one is using V now, but only because one is such a proficient speaker of German.

4. Rationalization: One copes with the discomfort of the foreign behaviour by convincing oneself that this is only done to achieve a higher goal. $\mathrm{V}$ is only used in order to reach a good agreement with someone or to get a good grade for the exam.

5. Confession-redemption: one accepts the discomfort but asks for redemption by promising not to do it again. One uses V in the classroom because one has to, but it would never happen again in a similar situation.

6. Host-VABN-rejection: one acknowledges the existence of the foreign behaviour, but explains one's unwillingness to adhere to the expectations. One explains states that one does not intend to use V (and possibly why).

In evaluating these different strategies it is important to recall that German is used as a language of instruction to help the students become proficient speakers of German. We want the students to acquire the intercultural skills necessary for interacting with Germans. Therefore viable strategies must be those providing a permanent solution to any discomfort caused by $\mathrm{V}$. The strategies in 3, 4, 5 and 6 do not appear to be of a lasting nature and presumably they will not assist the student in interacting with Germans in their future professional lives. ${ }^{11}$ The only viable strategies appear to be the first two ones. ${ }^{12}$

The strategy in 1 foresees modification of one's own VABN to match those of the target culture. It is not entirely clear how a teacher could go about changing a student's VABN and probably (s)he should not attempt to do so. Intercultural competence is not about changing one's own culture and one's own values. It is about acknowledging the VABN underlying a foreign cultural behaviour and negotiating an appropriate behaviour in a particular interaction. Thus the most viable approach appears to be the strategy in 2, namely perceptual modification.

\footnotetext{
${ }^{11}$ Although it could be argued that strategy 4 (Rationalization) is relevant in a business setting. Individuals use $\mathrm{V}$ to achieve their business goals with a foreign communication partner.

12 One can also accept that students use strategy 6 (Host-VABN-rejection) and reject the new VABN, but only if they do so deliberately. The students must explicitly decide not to use $\mathrm{V}$ and be able to explain why. Of course they must also be aware of the consequences.
} 
Perceptual modification means modifying one's perception of the foreign cultural behaviour to the extent that it no longer violates one's own VABN. In the present case, it means that V is no longer interpreted in the context of Danish culture, but in the context of German culture. It must be made clear to the students that $\mathrm{V}$ is the unmarked form of address in Germany (comparable to the use of $\mathrm{T}$ in Denmark) and that $\mathrm{V}$ is understood along a scale of social distance and not (necessarily) along a scale of power distance. As mentioned in section 2, V has different interpretations in Germany and Denmark and the words Sie/De and $d u / d u$ can be considered false friends in the lexicographic sense (similar words with different interpretations). Here, the dictionary could be valuable in achieving a perceptual modification. This is not yet the case though. The entry for Danish $d u$ in Gyldendals Dansk-Tysk ordbog ['DanishGerman Dictionary'] (1999/2007) is repeated below (slightly simplified):

$$
\mathrm{du}^{2} \text { (pers.pron) } \mathrm{du} ;(\ldots)
$$

The proposed translation of Danish $d u$ into German $d u$ is correct if one takes the translational equivalence to be "the personal pronoun in the 2 nd person singular". If the translational equivalence is based on the semantic-pragmatic content of $d u$ as "the unmarked address of a communication partner" (and this is presumably what a dictionary user would need), the translation into German should be Sie (cf. also Weinrich 2003: 104). The lexical entry should then list appropriate exceptions of the kind: unless the interlocutors are intimate friends, etc.

In the case of $\mathrm{V}$, perceptual modification could start with close attention to the semantics of the linguistic expressions involved in the foreign cultural behaviour and a discussion of relevant contextual factors. This would be a good starting point for a more elaborate and thorough discussion in class.

\section{$5 \quad$ Which factors condition Cross-Cultural Code Switching?}

Conventions of address differ between cultures, but exactly under what circumstances is a special set of conventions supposed (or expected) to apply? In our (simplified) prototypical case, German conventions apply when a German speaks German to another German in Germany. Thus relevant categories appear to be the cultural backgrounds of the speaker and hearer, the language, and the environment. No problems arise if there is a perfect match between environment, language and the cultural backgrounds of speaker and hearer. But what happens if there is no such perfect match, i. e. if a Dane speaks German to a German in Denmark or if two Germans speak German in New Zealand? Which of the proposed categories are crucial for the choice of conventions? The literature is sparse on this topic, but relevant observations can be assembled from investigations of interactional behaviours.

Rasmussen (1998) investigates business phone calls between Danes and Germans. She observes that both the Danes and the Germans vary in their choice of either German or Danish conventions not only from one interaction to the next, but also within a single interaction. However, there is a tendency for them to use their respective defaults of address (the Danes using $\mathrm{T}$ and the Germans using $\mathrm{V}$ ) even within a single interaction. Here the cultural background of the speaker and the environment appear to determine the choice of conventions for both communication partners, with the speakers only occasionally adjusting to the conven- 
tions associated with the cultural background of the hearer. Crucially, no intercultural conflicts arise since both interlocutors are aware of the unmarked modes of address of the other.

Stoffel (1983/84, based on the discussion in Besch 1998) investigates the use of address forms among German immigrants in New Zealand. Here the environment has a different set of conventions than the one associated with the language used and with the (primary) cultural backgrounds of the interlocutors. Stoffel observes that German immigrants tend to follow the German conventions (predominantly V), but she also notes that the conventions may not be exactly like those in Germany (relevant factors are very complex). Here the language and the (primary) cultural backgrounds of the interlocutors appear to prevail in the choice of conventions.

So what is the situation like in the educational sector? In a study on the acquisition of the V/T-distinction in Dutch by British students, Vismans (2009) briefly discusses the behaviour of Dutch language instructors in Britain. He notes that they tend to use $\mathrm{T}$ even though $\mathrm{V}$ is still common at Dutch universities (Inger Mees p. c. 2016). ${ }^{13}$ Here the environment and the cultural background of the hearer prevail. Interestingly, he mentions that the situation is different for German instructors in Britain, who tend to use V following German conventions. For the German instructors the language and the cultural background of the speaker prevail. Besch (1998: 132-137), finally, contains a contribution by an Indian teacher of German. She reports that $\mathrm{V}$ is used in all courses taught in German at her university in India regardless of the cultural backgrounds of the speaker and hearer. She mentions herself that German conventions are followed (cf. Bresch 1998: 132), but it is not quite clear to what extent these conventions deviate from the conventions of the environment. However, the decisive factor appears to be the language.

I have only little data on the educational sector in Denmark and Germany and the following is based on informal discussions with colleagues. Native Danes tend to use $\mathrm{T}$ when teaching in German in Denmark. Here the cultural backgrounds of speaker and hearer as well as the environment appear to determine the choice of conventions. Native Germans vary in their choice according to the duration of their stay in Denmark. Germans who have been in Denmark for a longer period of time tend to use $\mathrm{T}$ following the environment and the cultural background of the hearer. Those who have only recently come to Denmark tend to use V in accordance with the cultural background of the speaker and the language.

In a similar fashion it is interesting to investigate what Germans and Danes do when they teach in Danish in Germany. At the university of Hamburg, T appears to be the choice for both the native Germans and the native Danes. In this case the choice of conventions follows the language and neither the environment nor the cultural backgrounds of Speaker and Hearer appear to be decisive.

The following table summarises the findings on the choice of $\mathrm{V}$ and $\mathrm{T}$ in higher education in Germany and Denmark:

\footnotetext{
${ }^{13}$ Interestingly, he reports that the students find the use of $\mathrm{T}$ dissatisfactory since it prevents them from discovering the complexities of the Dutch system at home (cf. Vismans 2007: 227).
} 


\begin{tabular}{|l|c|c|c|c|c|}
\hline & Environment & Language of instruction & $\begin{array}{c}\text { Culture of } \\
\text { speaker }\end{array}$ & $\begin{array}{c}\text { Culture of } \\
\text { hearer }\end{array}$ & Conventions \\
\hline 1. & GER & DK & GER & GER & DK \\
\hline 2. & GER & DK & DK & GER & DK \\
\hline 3. & DK & GER & DK & DK & DK \\
\hline 4. & DK & GER & GER & DK & DK/GER \\
\hline
\end{tabular}

Table 4: The choice of cultural conventions along with influencing factors

It emerges from this table, that Danish conventions of address prevail, but for different reasons. In Germany, Danish conventions are used in accordance with the language (or rather the rules of the country where the language is spoken), and in Denmark Danish conventions are used following the environment. Thus we find an interesting asymmetry in the choice of conventions in Germany and Denmark.

All in all, no clear picture emerges as to what determines the choice of conventions for forms of address, but the present discussion has uncovered a number of relevant factors. Determining factors can be the cultural backgrounds of speaker and hearer, the environment and sometimes only the language. Moreover, the importance of these factors appears to vary from country to country. The relative importance of the various factors needs to be further investigated as well as the possible influence of other contextual aspects. Still the table allows us to generate some hypotheses about the choice of cultural conventions and it may form the basis for a more comprehensive investigation of the context of cultural behaviours. In the light of these findings it becomes highly relevant to address the question of whether we need CrossCultural Code-Switching in the classroom and under what circumstances. So we need to consider which factors argue in favour and which factors against using German conventions when teaching in German - not the least considering the discussion of Cultural Cognitive Dissonance in section 4 .

\section{Cross-Cultural Code-Switching in the classroom?}

As we have seen, many factors are at stake when people decide to engage in Cross-Cultural Code-Switching. The fundamental question is: should we code-switch in foreign language instruction at home? In this section, I shall consider the pros and cons of code-switching in the classroom.

\subsection{Arguments in favour of using $V$ when German is the language of instruction}

The arguments in favour of using $\mathrm{V}$ with German as the language of instructions pertain to the furthering of intercultural competence, the importance of authentic interaction, the scope of cultural differences and alleviation of the linguistic burden for the students.

\section{Furthering intercultural competence}

As mentioned in the introduction, in the courses at CBS German is used as the language of instruction for educational purposes. Out objective is for the students to develop their lan- 
guage skills also when working on other (possibly non-linguistic) topics. However, language skills are not restricted to the linguistic code. The goal is also to educate language workers with a high level of intercultural and interactional competence (cf. Byram 1997; Kramsch 1993). According to Byram, an intercultural speaker must be able to identify differences and similarities between interactional behaviours and negotiate the appropriate use in a specific situation (cf. Byram 1997: 62). Forms of address constitute an intercultural and interactional behaviour which is not only frequently used but is also reflected linguistically. Ability to identify a foreign behaviour and to negotiate an appropriate use develops when one is exposed to divergent cultural behaviours. A proficient intercultural speaker is not expected to adopt a foreign behaviour (cf. Meißner 2013: 51), but knowledge of the foreign behaviour and ability to reflect on it is a prerequisite for coping with cultural differences in interactions. As shown by Rasmussen (1998), speakers may not adopt the same conventions in actual interactions, but they accept foreign conventions because they are aware of them. In higher education the German convention stipulates $\mathrm{V}$, so this particular situation offers an opportunity to expose the students to a foreign cultural behaviour without introducing role-play. It even offers an opportunity to train the unmarked form of address, namely $\mathrm{V}$, which is the core difference between the German and the Danish conventions. By using V in naturally occurring interaction, the students are introduced to the unmarked form of address without the teacher having to devise special kinds of exercises. Continuous use gives them opportunity to get used to it.

Having a Danish teacher using German conventions in a Danish context may even turn out to be an advantage for intercultural learning. The teacher will have to switch between $\mathrm{V}$ when speaking German and T when speaking Danish. This somewhat extraordinary behaviour represents a kind of "Verfremdungseffekt" ['alienation effect'] and forces the students to pay attention to this specific behaviour. It forces them to reflect on their own use of $\mathrm{V} / \mathrm{T}$ and its use in Denmark. As a matter of fact, the critical student evaluations mentioned in sections 1 and 4 testify to the usefulness of exposing the students to this kind of foreign behaviour: the students have reflected on the foreign behaviour and they have decided for themselves what is the appropriate form of address in a Danish educational context. Critical reactions help to develop the students' intercultural competencies as opposed to no reaction at all.

In addition Lörscher/Schulze (1988) and Kasper (1990) note that politeness does not form a natural part of the interaction in the classroom since the classroom is predominantly a locus for instructional discourse (cf. Kasper 1990: 195). In order to train interactional discourse, politeness should be introduced into the classroom discourse. Their conclusion supports the use of $\mathrm{V}$ since politeness strategies find a natural place in an authentic interactional discourse. ${ }^{14}$

\section{Creating authentic interactions}

Admittedly, a Danish educational context is not a natural setting for using German conventions. Still, the fact that both the lecturer and students interact in German though sharing another native language is unnatural in the first place. Speaking German with Danish conven-

\footnotetext{
14 Note, however, that Lörscher/Schulze (1988) also say that the institutional features of the school are an obstacle to re-organizing the teaching in accordance with politeness strategies. Rather, politeness should be taught in special phases of the lessons. It is not entirely clear to me how they arrive at this conclusion.
} 
tions of address would make the whole situation even more unnatural, or even slightly absurd, as if we are afraid of taking the final step and pretend to be in a genuine German setting.

A frequent argument for not using $\mathrm{V}$ put forward in the student evaluations is that we are in Denmark after all. Still, what would happen if we insist on always following the conventions of the environment? Take the example of Danish as the language of instruction in Germany. If we follow the line of reasoning above, we would have to follow the German conventions and use V. Students of Danish in Germany would become familiar with a form of address in class that they would hardly ever use in interactions with native Danes. This makes very little sense and is also the reason that Danish conventions are used in corresponding courses in Germany. If the goal of foreign language teaching is to make the students capable of interacting with native speakers of the language, we have a strong argument for giving the students the opportunity to get used to these particular modes of address already when learning the language at home.

\section{Determining the scope of cultural differences}

If we choose to ignore the conventions of address in German (and thus use $\mathrm{T}$ in higher education), we have to decide what other cultural differences should be ignored in German language instruction in Denmark as well. Forms of address are not the only cultural difference with a linguistic reflex. German also maintains a distinction between male and female professional titles: Arzt 'doctor.M'/Ärztin 'doctor.F', Politiker 'politician.M'/Politikerin 'politician.F'. Danish no longer makes this distinction ${ }^{15}$ - there are vestiges, but the distinction is not productive. If the environment is the factor that determines what cultural conventions to use, we should follow the Danish conventions and we should not distinguish male and female occupational titles when speaking German in a Danish environment either. Students should still learn to make this distinction in Germany though, but it would not be part of their training at home or only in tailor-made exercises. It appears to make little sense to complicate things by ignoring crucial differences between the languages in the basic training and it would ultimately lead to a variety of German only used in Danish classrooms. If we consistently adhere to the German conventions (and use V in higher education), we don't have to bother about these other cultural differences in the linguistic code. They will be a natural part of the linguistic interaction and the students will be prepared for interactions with native Germans.

\section{Alleviating the linguistic burden}

Finally, we may add a more linguistically oriented pedagogical argument in favour of using $\mathrm{V}: \mathrm{V}$ is less error-prone. If one opts for $\mathrm{T}$, one has to distinguish the singular and the plural address form ( $d u$ vs. $I h r)$ with the corresponding morphological changes of the verb, liest 'read.2P.SG' vs. lest 'read.2P.PL'. Moreover, one has to distinguish the imperative from the indicative in the singular: Lies den Text vor! 'Read the text aloud!' vs. Liest Du den Text vor? 'Would you read the text aloud?'. The V-pronoun Sie on the other hand is used for both singular and plural addressees and it requires no special form for the imperative (apart from the verb sein 'to be' with the imperative Seien Sie so nett! (lit.) 'be.IMP you so kind'). With V the

\footnotetext{
15 German distinguishes a Blogger 'blogger.M' from a Bloggerin 'blogger.F'. Bloggerin has more than a million occurrences in a Google search (29.01.2016). The corresponding Danish female form bloggerinde 'blogger.F' only occurs app. 1300 times and apparently only when it is used jokingly.
} 
verb is always in the third person plural, which happens to be identical to the infinitive, which is also used as the base form for dictionary entries.

\subsection{Arguments against using $\mathrm{V}$ when German is the language of instruction}

Nevertheless there are also reasons for not using V when teaching in German in Denmark. The arguments pertain to the (lack of) authenticity of the intercultural encounter in the classroom and to the risk of hitting mental barriers to the detriment of learning the foreign language.

\section{The authenticity of intercultural encounters}

As already mentioned above, the teaching context does not constitute a genuine intercultural encounter. Teacher and students are members of the same culture and the use of foreign cultural conventions is artificial in the current setting. A Danish learning environment invariably evokes Danish structures of expectation (cf. Kramsch 1993: 42-43, 1998: 26) with $T$ as the default mode of address. Structures of expectation serve to help members of a certain culture to interpret their surroundings, and a violation of these expectations may result in a negative attitude towards the teaching. The learning environment is felt to be unsafe, thus preventing the students from taking personal risks like adopting a foreign behaviour and speaking a foreign language.

It may even be undesirable to try to create a "little Germany" in the classroom. For Kramsch (1993) the classroom is a "Third place", a hybrid space within the language learners themselves, a transformative construction (cf. Huhtala/Lehti-Eklund 2010). The language learners are in between two cultures and the notion of the classroom as a "Third place" ties in with a view of intercultural communication as an intermediate culture between $\mathrm{C} 1$ and $\mathrm{C} 2$ and not an adoption of $\mathrm{C} 2$. Once we recognize that the classroom is neither "little Germany", nor entirely "Denmark" (we wouldn't be speaking German otherwise), we can make room for a flexible way of using $\mathrm{V}$ and $\mathrm{T}$ which conforms neither entirely to the Danish nor to the German conventions. In fact, it may not even be possible to create a "little Germany". Although we speak German, other modes of interaction may still be Danish. Fredsted (2004) documents that Danes use more paralinguistic and non-verbal politeness markers than Germans. Kramsch (1993: 85) shows that Germans employ a special discussion style or ways of expressing opinions. Even a very proficient speaker of German with a Danish background may not be able to adopt this behaviour and so any attempt to recreate a "little Germany" is doomed to fail.

Also, we run the risk of turning intercultural competence into a matter of being able to do as the Germans do. Intercultural competence, however, is not a matter of adopting a foreign culture (cf. Meißner 2013: 51). In Byram's (1997: 62) view, the intercultural speaker is someone who can identify and interpret cultural differences in intercultural encounters and negotiate an appropriate use of such conventions. In order to do so, the students must develop metacognitive skills. This is not achieved by making the students switch more or less automatically between different address conventions according to the language they are using. By employing a flexible scheme of address combining conventions from different cultures (cf. Byram 1997: 62), the students are encouraged to pay attention to the particular kind of situation and to the behaviour of the interlocutors (cf. also Liddicoat 2006 for a similar view 
on making students reflect on the use of address forms). Adopting this approach would indeed enhance the intercultural competence of the students and perhaps be more fruitful than just making them use $\mathrm{V}$ when the lesson starts and stop doing so when it ends.

\section{Hitting mental barriers}

An important - and often neglected - factor is that the use of unfamiliar forms of address may be in conflict with ingrained values and attitudes. Besch (1998: 131) speaks of "seelische Barrieren" ['mental barriers'] and presents some case studies where the use of V vs. T causes emotional distress. As extensively discussed above, there is reason to believe that Danish students experience cultural cognitive dissonance when using V. Danish society conceives of itself as embracing egalitarian values and $\mathrm{V}$ appears to be associated with power distance in violation of these egalitarian values. Moreover, such emotional distress is exacerbated by the fact that the students have to speak a foreign language and possibly have a feeling of not being able to express themselves without difficulties. Avoiding $\mathrm{V}$ will alleviate such conflicts and will help the students to concentrate on learning the foreign language.

\section{Conclusion}

In this article I have discussed two questions which are only rarely addressed: (1) why do (young) Danes have difficulties using the German V-forms? and (2) how do we determine when a culturally-based behaviour should apply? The specific case was an instructional setting where a course is taught in a (foreign) language associated with conventions of address different from those of the environment.

I have proposed and discussed the hypothesis that the choice between $\mathrm{V}$ and $\mathrm{T}$ is a case of Cross-Cultural Code-Switching and not merely a matter of knowing when to use the appropriate forms. The use of $\mathrm{V}$ may be associated with cognitive dissonance in an environment embracing egalitarian values, especially if $\mathrm{V}$ is associated with power distance. The teaching context invites such an interpretation and teachers should be aware of this and take action to mitigate cognitive dissonance when teaching foreign cultural behaviours. In this respect, Cross-Cultural Code-Switching appears to be a fruitful area for further research into the teaching of intercultural competences.

The second question concerns the applicability of foreign cultural behaviours in an educational setting. Do cultural behaviours come with the language or do they follow the environment? I have shown that there is no clear-cut answer to this question and that the factors involved in determining the applicability of cultural behaviours are poorly understood. Still as teachers of a foreign language we are constantly faced with this problem and obviously have to make a choice - and this choice should be based on careful consideration.

In this specific case, I recommend following the conventions associated with the foreign language given that intercultural competence is a learning objective. Thus, I would recommend to follow the German conventions and to use V when teaching in German in Denmark. There are a small number of arguments against using $\mathrm{V}$, but I believe that the arguments in favour of using $\mathrm{V}$ outweigh the ones against. In order to educate proficient intercultural speakers, it is important to expose the students to the foreign German behaviour instead of re-creating Denmark in German. The students are not necessarily obliged to assimilate to the foreign conven- 
tions, but they should be given the opportunity to interact with speakers using the foreign behaviour. Only through exposure will they be trained in paying attention to foreign behaviours and to react appropriately in actual interactions.

However, V must be carefully introduced and the use of $\mathrm{V}$ should be critically assessed and discussed at regular intervals, given that this is no true intercultural encounter (the teacher being Danish). It should also be possible to use $\mathrm{V}$ without doing so in an all-or-nothing fashion. $\mathrm{V}$ is symmetric in Germany, but it should be possible for the students to stick to the Danish $\mathrm{T}$ when addressing the lecturer as long as they are encouraged to be aware of what they are doing. Alternatively, $\mathrm{V}$ could be used symmetrically in parts of the course instead of during the entire course. This kind of hybrid address conventions is in line with the conception of the classroom as a "Third Place" distinct from both the native culture and the target culture. But substantial elements of the target culture still form part of this "Third place". Flexible forms of address with a certain degree of freedom in the choice of address forms will counterbalance inconveniences experienced by the students by speaking a foreign language, and it solves the problem of having the lecturer superimpose a foreign behaviour on the students. In addition, it would be advisable for the institutions or the individual departments to have a policy for adopting foreign cultural behaviours in CLIL-courses.

\section{References}

Bayer, Klaus (1979): „Die Anredepronomina ,Du“ und ,Sie““. Deutsche Sprache 7: 212-219.

Besch, Werner (1998): Duzen, Siezen, titulieren. Zur Anrede im Deutschen heute und gestern. Göttingen: Vandenhoeck \& Ruprecht.

Bork, Egon et al. (1999/2007): Gyldendal dansk-tysk ordbog. Copenhagen: Gyldendal.

Brown, Roger/Gilman, Albert (1960): "The pronouns of power and solidarity". In: Sebeok. Thomas A. (ed.): Style in Language. Cambridge, MIT: 253-276.

Bryld, Tina (2011): „Nu vi er dus med høfligheden“. Interview with Jørn Lund. Jyllandsposten 08.02.2011.

Byram, Michael (1997): Teaching and Assessing Intercultural Communicative Competence. Clevedon: Multilingual matters.

Cook, Manuela (2014): "Beyond T and V - Theoretical Reflections on the Analysis of Forms of Address". American Journal of Linguistics 3/1: 17-26.

Durrell, Martin (2007): „Anredegewohnheiten im Deutschen und Englischen“. In: Behr, Irmtraud/Larrory, Anne/Samson, Gunhild (eds.): Der Ausdruck der Person im Deutschen. Tübingen, Stauffenburg: 89-100.

Fink, Dagmar (2012): Business-dances with Danes. Decoding Danish workplace culture. Copenhagen: Worktrotter Publishing.

Fredsted, Elin (2004): "Politeness in Denmark: Getting to the point". In: Hickey, Leo/Stewart, Miranda (eds.): Politeness in Europe. Clevedon/GBR, Multilingual Matters: 159-174.

Harder, Peter (1980): "Discourse as Self-Expression - On the Reduced Personality of the Second-Language Learner". Applied linguistics 3: 262-270.

Heringer, Hans-Jürgen (2009): „Duzen und Siezen revisited“. In: Ehrhardt, Claus/Neuland, Eva (eds.): Sprachliche Höflichkeit in interkultureller Kommunikation und im DaFUnterricht. Frankfurt a. M., Lang: 61-75. 
Hofstede, Geert/Hofstede, Geert-Jan/Minkov, Michael (1991): Kulturer og organisationer. Copenhagen: Schultz.

Huhtala, Anna/Lehti-Eklund, Hanna (2010): "Writing a new self in the third place: language students and identity formation". Pedagogy, Culture \& Society 18/3: 273-288.

Jenkins, Richard (2011): Being Danish: Paradoxes of Identity in Everyday Life. Copenhagen: Museum Tusculanum.

Kasper, Gabriele (1990): “Linguistic Politeness”. Journal of Pragmatics 14: 193-218.

Knudsen, Anne (1996): Her går det godt - send flere penge. Copenhagen: Gyldendal.

Kramsch, Claire (1993): Context and Culture in Language Teaching. Oxford: Oxford University Press.

Kramsch, Claire (1998): Language and Culture. Oxford: Oxford University Press.

Kretzenbacher, Heinz L. (2010): „,Man ordnet ja bestimmte Leute irgendwo ein für sich ... Anrede und soziale Deixis“. Deutsche Sprache 1/10: 1-19.

Leech, Geoffrey N. (1983): Principles of pragmatics. London/New York: Longman.

Liddicoat, Anthony J. (2006): "Learning the culture of interpersonal relationships: Students' understandings of personal address forms in French". Intercultural Pragmatics 3/1: 55-80.

Lörscher, Wolfgang/Schulze, Rainer (1988): “On polite speaking and foreign language classroom discourse". International Review of Applied Linguistics in Language Teaching (IRAL) 26: 183-199.

Maertz Jr., Carl P./Hassan, Ahmad/Magnusson, Peter (2009): "When learning is not enough: A process model of expatriate adjustment as cultural cognitive dissonance reduction". Organization Behavior and Human Decision Processes 108: 66-78.

Meißner, Franz-Josef (2013): Die REPA-Deskriptoren der ,weichen' Kompetenzen. Eine praktische Handreichung für den kompetenzorientierten Unterricht zur Förderung von Sprachlernkompetenz, interkulturellem Lernen und Mehrsprachigkeit. Gießen: Universitätsbibliothek. http://geb.uni-giessen.de/geb/volltexte/2013/9372/pdf/GiFon-Bd2.pdf [13.02.2016].

Molinsky, Andrew (2007): "Cross-Cultural Code-Switching: The psychological challenges of adapting behavior in foreign cultural interactions". Academy of Management Review 32/2: 622-640.

Morford, Janet (1997): "Social indexicality in French pronominal address". Journal of Linguistic Anthropology 7/1:3-37.

Møller, Henrik R. (2008): „Tyskland“. In: Palmgren, Ulla Gjedde (ed.): Håndbog i høflighed - kulturelle koder i elleve EU-lande. Copenhagen: Multivers.

Nikula, Tarja (2010): "Effects of CLIL on a teacher's classroom language use". In: DaltonPuffer, Christiane/Nikula, Tarja/Smit, Ute (eds.): Language Use and Language Learning in CLIL Classrooms. Amsterdam/Philadelphia, Benjamins: 115-125.

Nørmark, Dennis (2011): Kulturforståelse for stenalderhjerner. Viborg: Det Andersenske forlag.

Preisler, Bent (2014): "Lecturing in one's first language or in English as a lingua franca: The communication of authenticity". Acta Linguistica Hafniensia 46/2: 218-242.

Rasmussen, Gitte (1998): "The use of forms of address in intercultural business conversation”. Revue des Sémantique et Pragmatique 3: 57-72. 
Stoffel, Gertraud (1983/84): „Veränderungen und semantische Konflikte im Anredeverhalten Deutschsprachiger in Neuseeland“. Muttersprache 94: 185-193 (quoted after the discussion in Besch 1998).

Vismans, Roel (2009): “Advanced Learner's Use of Dutch Second Person Pronouns During Residence Abroad". Journal of Germanic Linguistics 21/2: 211-230.

Weinrich, Harald (2003): Textgrammatik der deutschen Sprache. Hildesheim: Olms. 